\title{
CONDUIT standards and procedures: A practical experience
}

\author{
TRINKA DUNNAGAN \\ CONDUIT/Central, lowa City, lowa 52240
}

Standards and procedures for the CONDUIT program are described.

In 1972 CONDUIT was funded by the National Science Foundation to study the exchange of computer-based instruction among institutions of higher learning. Ihe original CONDUIT consortium consisted of tive regional netuork centers with a variety of computing hardware and softuare. From cONDUIT", experience with sharing instructional programs among netuork schools, a set of standard requirements and procedures for exchange of instructional soltuare evolved. This set will be described in derelopmental stages.

The tirst problem addressed by CONDUIT was physical exchange anong the network sites: How do vou communicate between sender and recipient; how do you overcome machine incompatibilities when exchanging instructional software? By agreeing to a standard card image format on magnetic tape, a distribution form to accompany the tape, and the use of FORIRAN for source programs, CONDUIT munmi/ed this initial problen. As a first step, the decosion was important because all centers could read the standard tape, know what to expect in terms of contents, and deal with the programming language.

Our next concern was documentation for instructional software. An initial pass at guidelines for documenters focused on technical requirements for making a program as self-documenting as possible, while also supplying enough information for program implementers. Our strategy required the software developer (or sender) to make sure that the program was readable-well commented and clearly structured-and that the source code was system independent. (This strategy assigned the responsibility of making a program reusable to the developer instead of requiring every importer to re-perform this lask.) To achieve system independence, the consortium agreed to code in ANSI standard FORTRAN or, in the case of minicomputers, a CONDUIT subset of BASIC which had syntactic equivalents at all the sites. In addition, the sender was required to supply sample input output and test data with expected results to the recipient so that he could install and verify the programs on his system. Additional discussion of CONDUIT requirements and recommendations for exchangeable software is available in the CONDUIT Technical Transfer Guidelines (Dunnagan, 1975b).

In order to enforce the technical requirements for cONDUIT softuare. several standard procedures were utilued. All FORTRAN programs are now passed through an ANSI standard FORTRAN veritier obtained trom Bell Laboratories and then corrected to conlorm to ANSI standards. These programs are also run through POLISH, obtained from the University of colorado, for enhancement of the code. BASIC code. it not usable at other sites, is replaced by more transportable statements from CONDUIT's BASIC subset. All programs are tested and the test data and results appended to the technical documentation.

This approach to documentation, stressing technical aspects of instruction softw are, was found to be insufficient. When CONDUIT workshopped programs in several disciplines and on a national basis, the instructor's need for better instructional documentation became a significant issue. Subsequent experience has supported the conclusion that exchange of instructional software involves pedagogical as well as technological issues. To meet this need, the CONDUIT Documentation Guide was developed (Dunnagan, 1975a). The purpose of this guideline was to specify standard "packaging" for computer-based instruction. A CONDUIT standard package would contain, as much as possible, the following: (1) an abstract describing the substantive content. level, course application, and source of the material. (2) a student manual guiding student involvement in the instruction. (3) a teacher manual aiding the application of the instruction to a normal class-teaching situation, and (4) software with technical documentation.

Because packaging instructional software involved a substantial investment, CONDUIT recognized the need to formalize the process of selecting materials to be enhanced. With the help of CONDUIT curriculum advisory committees, a peer review system was instigated. Up to four reviewers rate each package on: (1) substantive content, (2) documentation/ textual materials, (3) support of the teaching process, 
(4) stimulation of student interest, (5) computer techniques/materials, and (6) overall evaluation of the package. The reviewer qualifies his judgment by describing an appropriate context for use of the materials. A tinal decision based upon these reviews is made by a CONDUIT advisory editor who decides whether to accept the package, recommend the package pending improvement, or drop it from CONDUIT consideration. Use of the review system allow's CONDUIT to select instructional software on the basis of how well the software meets criteria of acceptability, criteria based on our fundamental objective of identifying worthwhile instructional materials for possible distribution throughout the consortium.

CONDUIT's standard procedures and requirements for instructional software cannot solve all the problems of software exchange. To date, guidelines and standard procedures are defined iteratively on the basis of practical experience. We have focused our early attempts on batch-oriented FORTRAN programs of primary interest to the CONDUIT network centers. Our exploration of the problems with exchanging BASIC programs for minicomputers is underway. but leads to no ready answers.

We have addressed the issue of CAI and have learned that exchanging CAI requires theoretical work on automatic translation systems, and perhaps an interface CAI language.

There is certainly a wealth of approaches to computer-based education and many possibilities in CONDUIT's future. Attention to standardization issues can be seen not only as cautious pragmatism, but also as an exciting challenge in fostering the development and sharing of innovative education. perhaps even facilitating aeadenic rewards for serious educators.

\section{REFERENCES}

Dunnagan. Trinka. CONDLIT documentation guide. Iowa City, lowa: CONDUlT Central. 1975. (a)

Dunnagan, TrInka. CONDUIT technical transfer guidelines. Iowa City, lowa: CONDUIT/Central, 1975. (b)

JoHNSON. JaMES W. CONDUIT authors guide. lowa City, lowa: CONDUIT Central. 1975. 